\title{
Sonication-Assisted Mitsunobu Etherification of Sterically Encumbered and Intramolecular Hydrogen Demanding Compounds: A Model towards Intramolecular MPV Reduction
}

\author{
Reinner I Lerrick \\ School of Chemistry, University of Nusa Cendana Kupang \\ Jl. Adi Sucipto Kampus Baru Penfui Kupang 85001 \\ tel/fax : (+62)822-33548034, email: reinnerishaqlerrick@gmail.com
}

\begin{abstract}
A steric and intramolecular hydrogen bonding controlled substrates has been successfully etherified towards sonication assisted Mitsunobu reaction. This modified alcohol-alcohol coupling reaction of 2-hydroxyacetophenone, substituted 2-hydroxyecetophenone, benzophenone and substituted benzophenones with $(2 \mathrm{R}, 4 \mathrm{R})$-pentanediol was found to be substrate electronic restraint.
\end{abstract}

Keywords: Mitsunobu Etherification, Sonication, phenoxyketones

\section{INTRODUCTION}

Asymmetric reduction of prochiral carbonyls is among the most widely methods in assessing chiral substrates, amenable simply over substrates or hydrate types. Established Noyori method, a ruthenium based nobel price carbonyl reduction [1]-[3] and Corey-Bakhsi-Shibata (CBS) [4]-[6] method prove to perform high stereoselectivity carbonyl reduction producing in excellent yield and high \%ee of chiral alcohols. However, they are chiral catalyst demanding processes.

Chiral alcohols could also be accessed through intramolecular Aldol [7], Aldol-Tishchenko [8] and Meerwein-Pondorf-Verley (MPV) reduction [9]. These hydrides transfer processes known to be a high chemoselective and inexpensive method. Interestingly recent Thai's intramolecular MPV modification demonstrated high diasetereoselective alcohol access ((2) and (4)) simply over introduction of an optically active ether ((1) and (3) respectively) [10] as the hydride source (Figure 1).

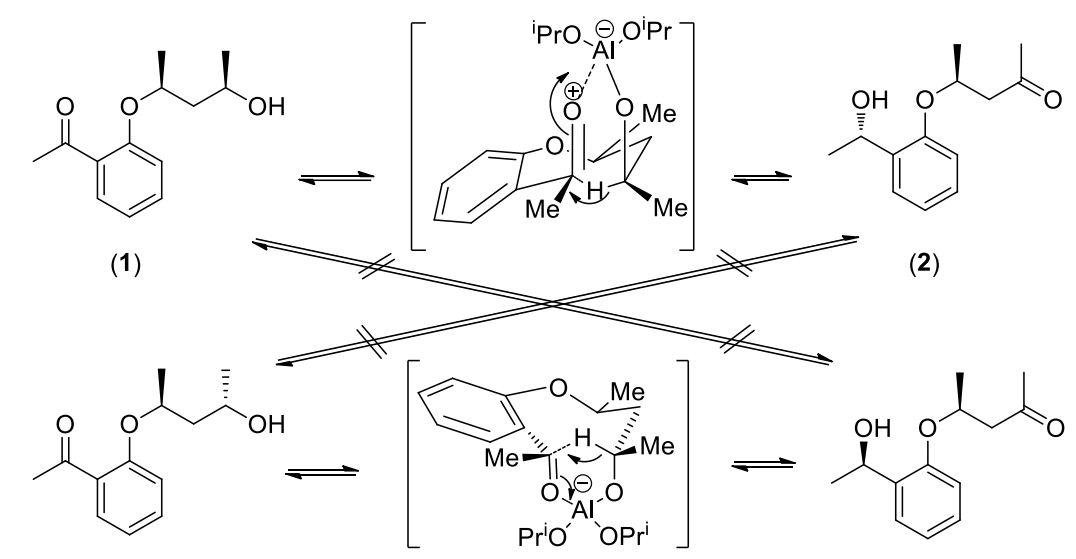

(3)

(4)

Figure 1 The Thai intramolecular 
Inspired by Thai, a biologically active diaromatic hydroxyl ketone (5) could allegedly be accessed over Thai's modified MPV of (7) becoming enantiopure (6) (Figure 2). The reason was due to similar phenoxy ketone system of (7) to that of Tai's substrate. Therefore, a simple synthesis of rarely synthesised (5) could then be generated.<smiles>O=C=CC1c2c(Cl)cc(Cl)cc2OCOC1c1[nH]c(Cl)c(Cl)c1[N+](=O)[O-]</smiles>

(5)<smiles>C=C=Cc1c(Cl)cc(Cl)c([C@H](O)c2[nH]c(Cl)c(Cl)c2[N+](=O)[O-])c1O</smiles>

(6)<smiles>O=C(c1cc(Cl)cc(Cl)c1O)c1[nH]c(Cl)c(Cl)c1[N+](=O)[O-]</smiles>

(7)

Figure 2 Retrosynthesis of (5)

This manuscript discusses preliminary attempts of synthesising chiral ether (7) towards a model in order to prepare (5). 2-hydroxyacetophenone and hydroxybenzophenone has been used as the model of (7) in undergoing Mitsunobu etherification with chiral diols. Getting successful conditions of the model could then be employed for (7).

\section{EXPERIMENTAL SECTION}

\subsection{Materials}

All chemicals used purely and purchased from Sigma Aldrich, TCI and AlfaAesar. Solvents used were dried.

Instrumentation

Sonication reactions were done using $60 \mathrm{~Hz}$ Decon FS 100b sonicator. Proton and 13-carbon magnetic resonance used $300 \mathrm{MHz}$ Bruker Avance BVT3200 spectrometer and $400 \mathrm{MHz}$ Jeol JNM ECS400 spectrometer, respectively. Infra-red analysis used Varian 800 FT-IR Scimitar Series spectrometer scanning and Micromass LCT Premier Mass Spectrometer in Electron Spray (ES) mode were used for mass analysis.

\subsection{Procedure}

Synthesis 2-propoxyacetophenone (9)

To a round bottom flask was added sequentially 2 -hydroxyacetophenone ( $0.68 \mathrm{~g}, 5 \mathrm{mmol})$, DEAD (0.87 g, $5 \mathrm{mmol})$, Sodium benzoate $(0.71 \mathrm{~g}, 5 \mathrm{mmol})$ in THF $(20 \mathrm{~mL})$ while into other flask was added solution of 1propanol $(0.3 \mathrm{~g}, 5 \mathrm{mmol})$, Ph3P $(1.31 \mathrm{~g}, 5 \mathrm{mmol})$ and THF $(5 \mathrm{~mL})$. into flask one then added solution from flask two through syringe. The solution was stirred for $4 \mathrm{~d}$. solvent was removed under pressure to give oil residue. The crude product then purified through column chromatography under elution of petrol 40/60 : methanol : ethylacetate $=200: 3: 1$ to give colourless oil $(0.53 \mathrm{~g}, 60 \%) . \mathrm{Rf}=0.39 ; 1 \mathrm{H}-\mathrm{NMR}(300$ MHz,CDCl3): 7.65 (dd, J = 7.6, 1.2 Hz, 1H), 7.36-7.31 (m, 1H), 6.89-6.82 (m, 2H), $3.92(\mathrm{t}, \mathrm{J}=6.4 \mathrm{~Hz}, 2 \mathrm{H})$, 1.84-1.72 (m, 2H), 0.99 (t, J = 7.4 Hz, 3H); 13C-NMR (100 MHz, CDCl3): 10.8, 22.5, 32.1, 70.0, 112.2, 120.4, 128.2, 130.4, 133.6, 158.5, 199.9; IR (neat, cm-1): 2968.7, 2879.9, 1665.5; HRMS (MH+): 179.1065.

Synthesis (1'S, 3 'R)-2-(3'-Hydroxy-1'-methylbutoxy)acetophenone (10)

To a round bottom flask was added sequentially 2-hydroxyacetophenone (69 mg, $0.51 \mathrm{mmol}),(2 \mathrm{R}, 4 \mathrm{R})$ pentanediol (56 mg, $0.54 \mathrm{mmol}), \mathrm{Ph} 3 \mathrm{P}(141 \mathrm{mg}, 5 \mathrm{mmol})$ and THF $(0.2 \mathrm{~mL})$. The mixture then sonicated for $15 \mathrm{~min}$. while sonicating, DEAD (94 mg, $0.54 \mathrm{mmol}$ ), was added into flask the solution through syringe. The solution was stirred for $10 \mathrm{~min}$ at $42 \mathrm{oC}$. The solution was triturated with cool petrol and purified through column chromatography using petrol 40/60 : ethylacetate $=1: 5$ to give colourless oil $(72 \mathrm{mg}, 64 \%)$. $\mathrm{Rf}=$ 0.67; 1H-NMR (300 MHz,CDCl3): $7.63(\mathrm{dd}, \mathrm{J}=7.71 .8 \mathrm{~Hz}, 1 \mathrm{H}), 7.40-7.33(\mathrm{~m}, 1 \mathrm{H}), 6.96-6.92(\mathrm{~m}, 1 \mathrm{H})$, $6.89(\mathrm{dd}, \mathrm{J}=7.7,1.8 \mathrm{~Hz}, 1 \mathrm{H}), 4.73-4.62(\mathrm{~m}, 1 \mathrm{H}), 4.00-3.90(\mathrm{~m}, 1 \mathrm{H}), 2.95(\mathrm{~s}, 1 \mathrm{H}), 2.53(\mathrm{~s}, 3 \mathrm{H}), 1.97$ (ddd, J $=14.3,8.9,7.4 \mathrm{~Hz}, 1 \mathrm{H}), 1.66(\mathrm{ddd}, \mathrm{J}=14.3,8.9,7.4 \mathrm{~Hz}, 1 \mathrm{H}), 1.30(\mathrm{~d}, \mathrm{~J}=6.0 \mathrm{~Hz}, 3 \mathrm{H}), 1.18(\mathrm{~d}, \mathrm{~J}=6.2 \mathrm{~Hz}$, 3H); 13C-NMR (100 MHz, CDCl3): 19.7, 24.1, 31.4, 45.5, 66.2, 73.2, 113.4, 120.4, 129.0, 130.7, 133.5, 156.6, 199.9; IR (neat, cm-1): 3429.8, 2973.1, 2932.5, 1719.8; HRMS (MH+): 223.1329. 
Synthesis (1 'S, 3'R)-2-(3'-Hydroxy-1'-methylbutoxy)-4-methoxyacetophenone (15)

To a round bottom flask was added sequentially 2 -hydroxy-4-methoxyacetophenone $(85 \mathrm{mg}, 0.51 \mathrm{mmol})$, (2R,4R)-pentanediol (56 mg, $0.54 \mathrm{mmol})$, Ph3P (141 mg, $5 \mathrm{mmol})$ and THF $(0.2 \mathrm{~mL})$. The mixture then sonicated for $15 \mathrm{~min}$. While sonicating, DEAD (94 mg, $0.54 \mathrm{mmol})$, was added into flask the solution through syringe. The solution was stirred for $25 \mathrm{~min}$ at $42 \mathrm{oC}$. The solution was triturated with cool petrol and purified through column chromatography using petrol 40/60 : ethylacetate $=1: 5$ to give colourless oil (22 mg, 17\%). Rf = 0.60; 1H-NMR (300 MHz,CDCl3): $7.72(\mathrm{dd}, \mathrm{J}=8.61 .8 \mathrm{~Hz}, 1 \mathrm{H}), 6.46(\mathrm{dd}, \mathrm{J}=5.5,2.3$ $\mathrm{Hz}, 1 \mathrm{H}), 4.74-4.63(\mathrm{~m}, 1 \mathrm{H}), 4.04-3.94(\mathrm{~m}, 1 \mathrm{H}), 3.78$ (s, 3H), 2.49 (s, 3H), 2.97 (s, 1H), 1.98 (ddd, J = 14.3, 8.9,7.4 Hz, 1H), $1.69(\mathrm{ddd}, \mathrm{J}=14.3,8.9,7.4 \mathrm{~Hz}, 1 \mathrm{H}), 1.32(\mathrm{~d}, \mathrm{~J}=6.2 \mathrm{~Hz}, 3 \mathrm{H}), 1.18(\mathrm{~d}, \mathrm{~J}=6.2 \mathrm{~Hz}, 3 \mathrm{H}) ; 13 \mathrm{C}-$ NMR (100 MHz, CDCl3): 19.7, 31.3, 45.5, 66.1, 73.3, 100.2, 105.0, 121.7, 130.7, 133.0, 158.8, 164.4, 199.4; IR (neat, cm-1): 3423.6, 2971.7, 2933.3, 1724.8; HRMS (MH+): 253.1437.

Synthesis (1'S, 3'R)-2-(3'-Hydroxy-1'-methylbutoxy)-5-nitroacetophenone (16)

To a round bottom flask was added sequentially 2-hydroxy-5-nitroacetophenone (92 $\mathrm{mg}, 0.51 \mathrm{mmol})$, (2R,4R)-pentanediol $(56 \mathrm{mg}, 0.54 \mathrm{mmol}), \mathrm{Ph} 3 \mathrm{P}(141 \mathrm{mg}, 5 \mathrm{mmol})$ and THF $(0.2 \mathrm{~mL})$. The mixture then sonicated for $15 \mathrm{~min}$. While sonicating, DEAD $(94 \mathrm{mg}, 0.54 \mathrm{mmol})$, was added into flask the solution through syringe. The solution was stirred for $5 \mathrm{~min}$ at $42 \mathrm{oC}$. The solution was triturated with cool petrol and purified through column chromatography using petrol 40/60 : ethylacetate $=1: 5$ to give yellow oil $(71 \mathrm{mg}$, $52 \%) . \mathrm{Rf}=0.55 ; 1 \mathrm{H}-\mathrm{NMR}(300 \mathrm{MHz}, \mathrm{CDCl} 3): 8.53(\mathrm{~d}, \mathrm{~J}=2.9 \mathrm{~Hz}, 1 \mathrm{H}), 8.25(\mathrm{dd}, \mathrm{J}=9.2,2.9 \mathrm{~Hz}, 1 \mathrm{H}), 7.10$ $(\mathrm{d}, \mathrm{J}=9.2 \mathrm{~Hz}, 1 \mathrm{H}), 4.88-4.78(\mathrm{~m}, 1 \mathrm{H}), 3.99-3.88(\mathrm{~m}, 1 \mathrm{H}), 2.987(\mathrm{~s}, 1 \mathrm{H}), 2.57$ (s, 3H), 2.00 (ddd, J = 14.3, 8.9,7.4 Hz, 1H), $1.68(\mathrm{ddd}, \mathrm{J}=14.3,8.9,7.4 \mathrm{~Hz}, 1 \mathrm{H}), 1.40(\mathrm{~d}, \mathrm{~J}=6.0 \mathrm{~Hz}, 3 \mathrm{H}), 1.21(\mathrm{~d}, \mathrm{~J}=6.2 \mathrm{~Hz}, 3 \mathrm{H}) ; 13 \mathrm{C}-$ NMR (100 MHz, CDCl3): 19.6, 24.5, 31.4, 44.9, 65.5, 74.3, 113.5, 126.7, 128.5, 128.7, 140.6, 161.3, 197.4; IR (neat, cm-1): 3424.5, 2972.7, 2931.4, 1680.2; HRMS (MH+): 268.1182.

Synthesis (1'S, 3'R)-2-(3'-Hydroxy-1'-methylbutoxy)benzophenone (17)

To a round bottom flask was added sequentially 2-hydroxybenzophenone (101 $\mathrm{mg}, 0.51 \mathrm{mmol}),(2 \mathrm{R}, 4 \mathrm{R})$ pentanediol $(56 \mathrm{mg}, 0.54 \mathrm{mmol}), \mathrm{Ph} 3 \mathrm{P}(141 \mathrm{mg}, 5 \mathrm{mmol})$ and THF $(0.2 \mathrm{~mL})$. The mixture then sonicated for $15 \mathrm{~min}$. While sonicating, DEAD (94 mg, $0.54 \mathrm{mmol})$, was added into flask the solution through syringe. The solution was stirred for $2 \mathrm{~h}$ at $42 \mathrm{oC}$. The solution was triturated with cool petrol and purified through column chromatography using petrol 40/60 : ethylacetate $=1: 5$ to give colourless oil $(8 \mathrm{mg}, 6 \%)$. $\mathrm{Rf}=0.62$; 1H-NMR (300 MHz,CDCl3): 7.74-7.72 (m, 2H), 7.52-7.46 (m, 1H), 7.42-7.29 (m, 4H), 6.97- 6.92 (m, 2H), 4.58-4.48 (m, 1H), 3.82-3.72 (m, 1H), $2.90(\mathrm{~s}, 1 \mathrm{H}), 1.58(\mathrm{ddd}, \mathrm{J}=14.3,8.9,7.4 \mathrm{~Hz}, 1 \mathrm{H}), 1.48$ (ddd, J = 14.3, 8.9, 7.4 Hz, 1H), $1.14(\mathrm{~d}, \mathrm{~J}=6.2 \mathrm{~Hz}, 3 \mathrm{H}), 1.06(\mathrm{~d}, \mathrm{~J}=6.2 \mathrm{~Hz}, 3 \mathrm{H})$; 13C-NMR (100 MHz, CDCl3): 19.5, 23.8, 45.4, 66.4, 73.9, 113.7, 120.2, 128.2, 129.9, 130.5, 132.1, 132.8, 138.1, 155.5, 196.4; IR (neat, cm-1): 3475.2, 2973.4, 2932.7, 1657.0; HRMS (MH+): 285.1488.

Synthesis (1 'S, 3'R)-2-(3'-Hydroxy-1'-methylbutoxy)-4-methoxybenzophenone (18)

To a round bottom flask was added sequentially 2-hydroxy-4-methoxybenzophenone $(116 \mathrm{mg}, 0.51$ mmol), (2R,4R)-pentanediol (56 mg, $0.54 \mathrm{mmol})$, Ph3P (141 mg, $5 \mathrm{mmol})$ and THF (0.2 mL). The mixture then sonicated for $15 \mathrm{~min}$. While sonicating, DEAD (94 mg, $0.54 \mathrm{mmol})$, was added into flask the solution through syringe. The solution was stirred for $5 \mathrm{~h}$ at $42 \mathrm{oC}$. The solution was triturated with cool petrol and purified through column chromatography using petrol 40/60 : ethylacetate $=1: 5$ to give colourless oil (14 $\mathrm{mg}, 8 \%)$. Rf = 0.68; 1H-NMR (300 MHz,CDCl3): 7.70-7.68 (m, 2H), 7.50-7.44 (m, 1H), 7.37-7.32 (m, 3H), $6.47(\mathrm{~d}, \mathrm{~J}=9.3,2.1 \mathrm{~Hz}, 1 \mathrm{H}), 6.44(\mathrm{~d}, \mathrm{~J}=9.3,2.1 \mathrm{~Hz}, 1 \mathrm{H}), 4.54-4.44(\mathrm{~m}, 1 \mathrm{H}), 4.54-4.10(\mathrm{~m}, 1 \mathrm{H}), 2.88(\mathrm{~s}$, $1 \mathrm{H}), 1.51(\mathrm{ddd}, \mathrm{J}=14.3,8.9,7.4 \mathrm{~Hz}, 1 \mathrm{H}), 1.47(\mathrm{ddd}, \mathrm{J}=14.3,8.9,7.4 \mathrm{~Hz}, 1 \mathrm{H}), 1.17(\mathrm{~d}, \mathrm{~J}=6.2 \mathrm{~Hz}, 3 \mathrm{H}), 1.08$ (d, J = 6.2 Hz, 3H); 13C-NMR (100 MHz, CDCl3): 19.6, 24.1, 45.8, 55.9, 66.5, 74.3, 100.8, 104.7, 121.7, 128.4, 130.0, 132.6, 133.4, 139.7, 158.4, 163.8, 195.7; IR (neat, cm-1): 3459.1, 2980.7, 1648.7; HRMS $(\mathrm{MH}+): 315.1593$.

\section{RESULTS AND DISCUSSION}

\subsection{Reaction Optimisation}

Examination of Mitsunobu etherification over substrates 
Among those etherification methods, we employed Mitsunobu which is the most considerable alcoholalcohol coupling reaction especially in the case of low pKa alcohols, secondary or tertiary alcohols [11], including stereoselectivity consideration.

In order to test Mitsunobu reliability over our substrates, (8) was initially reacted with simple alcohol under Mitsunobu standard conditions (Table 1). Through this, conditions gave highest yield would then be employed for etherifying other substrates.<smiles>CC(=O)c1ccccc1O</smiles>

(8)

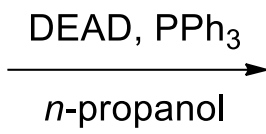

$n$-propanol<smiles>CCCOc1ccccc1C(C)=O</smiles>

(9)

Table 1 Reaction conditions of Mitsunobu etherification reaction of (8)

\begin{tabular}{llllll}
\hline Entry & Conditions & Solvent & Additives & Time (h) & $\begin{array}{l}\text { Isolated Yield } \\
(\%)\end{array}$ \\
\hline 1 & r.t. & THF & - & 96 & 0.5 \\
2 & r.t.-66 ${ }^{\circ} \mathrm{C}$ & THF & - & 96 & 25 \\
3 & r.t. & DCM & - & 96 & 0 \\
4 & r.t. & THF & 1 eq. Et ${ }_{3} \mathrm{~N}$ & 30 & 25 \\
5 & $66{ }^{\circ} \mathrm{C}$ & THF & 1 eq Et 3 & 48 & 45 \\
6 & r.t. $-66{ }^{\circ} \mathrm{C}$ & THF & Sodium benzoate & 48 & 60 \\
\hline
\end{tabular}

Table 1 showed a persevering Mitsunobu over 2-hydroxyacetophenone. Carrying the reaction under Mitsunobu standard conditions or under slight solvent change was unsuccessful (entry 1 and 3). Realising by the hydrogen bond controlled pKa nature of the substrate (8) [10], [12], we then attempted to break the intramolecular hydrogen bonding through reflux and/or acidic phenoxy deprotonation. In fact, these substrate $\mathrm{pH}$ modification efforts afforded the desired ether product (9) as shown in entry 2 and entry 4-6.

Spectroscopy analysis using 1H-NMR, 13C-NMR, HRMS and FT-IR strongly confirms the product as (9) (Figure 3).

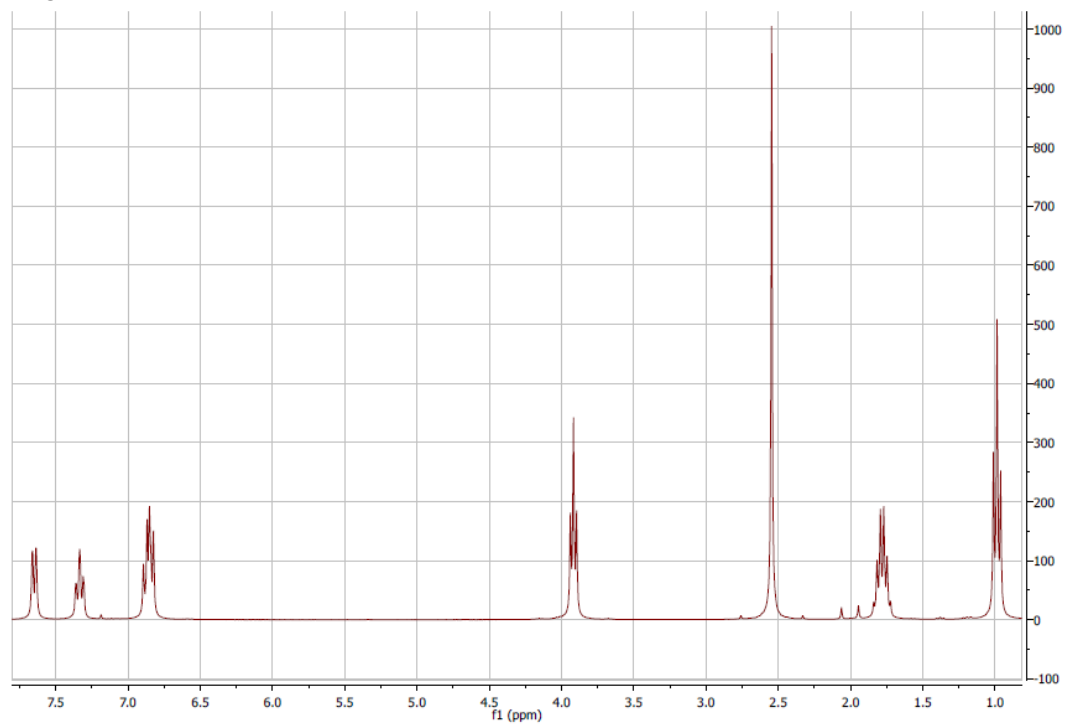

${ }^{13} \mathrm{C}-\mathrm{NMR}$ 
Reinner I Lerrick./ISoC Proceeding (1-10)

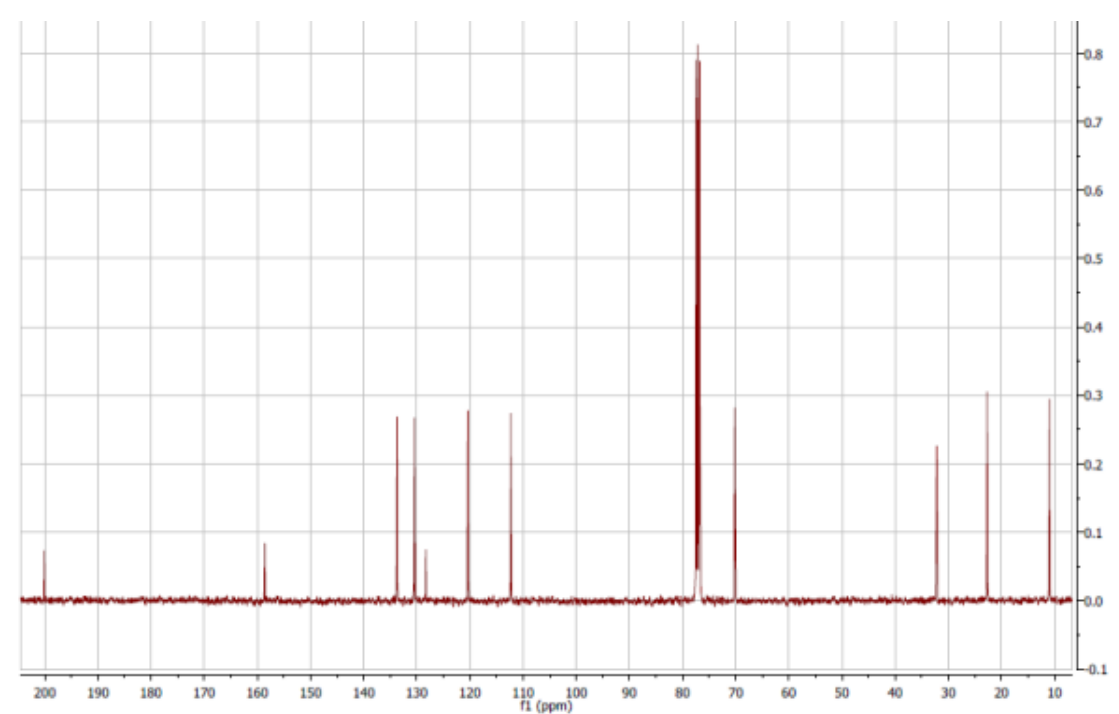

HRMS

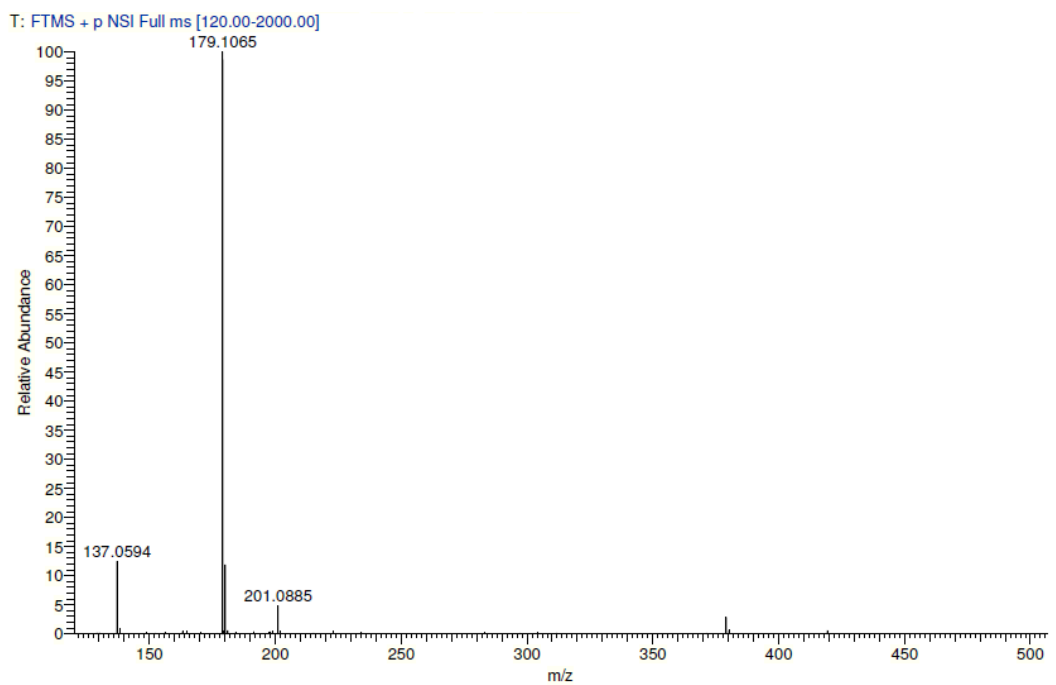

FT-IR

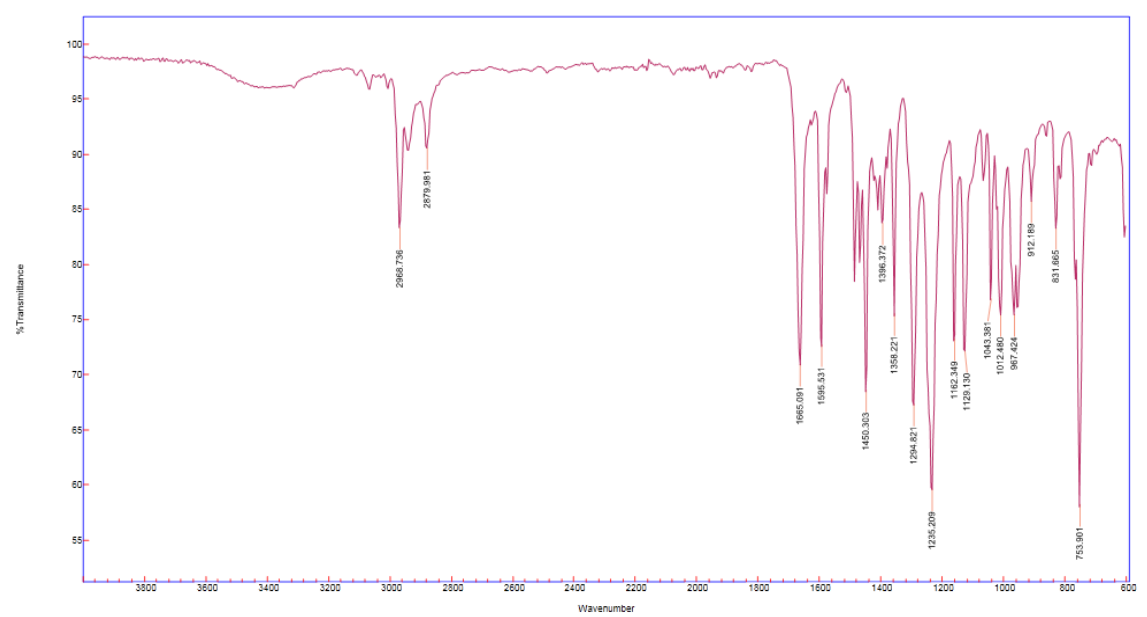

Figure 3 Spectroscopy data of (9) 


\section{Effort in Accessing Thai's Ethers}

Getting success with the preparation of (9) (Table 1 entry 6), (10) was then intended to be prepared. Submission of 2-hydroxyacetophenone to 2,4-pentanediol under sodium benzoate-reflux was, however, unsuccessful (Table 2 entry 1). Suggested by low pKa issue of both the substrate and the diol ( $\mathrm{pKa}=10$ and 16 respectively) [13], a more reactive azo coupling agent, ADDP (11) was used in the replacement of DEAD. This electron donating group containing azo could hopefully generate (13) and (14) proceeding to the product more easily (Figure 4). This though was still no reaction (entry 2 and 3).

Table 2 Optimisation reaction condition for the synthesis of (10)

\begin{tabular}{lllllll}
\hline Alcohol & $\begin{array}{l}\text { Coupling } \\
\text { Reagent }\end{array}$ & Additive & Temperature $\left({ }^{\circ} \mathrm{C}\right)$ & Solvent & Time & Yield $(\%)$ \\
\hline$( \pm)-2,4$-pentanediol & DEAD & $\begin{array}{l}\text { 1 eq. } \\
\text { Sodium } \\
\text { benzoate }\end{array}$ & r.t-66 & THF & 5 days & No reaction \\
$(2 R, 4 R)-(+)$-pentanediol & DEAD & $\begin{array}{l}1 \text { eq. } \\
\text { Sodium } \\
\text { benzoate }\end{array}$ & r.t-66 & THF & 5 days & No reaction \\
$(2 R, 4 R)-(+)$-pentanediol & ADDP & - & r.t-66 & THF & 5 days & No reaction \\
\hline
\end{tabular}

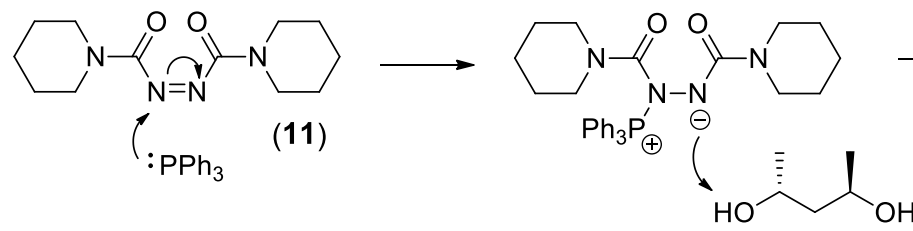

(12)
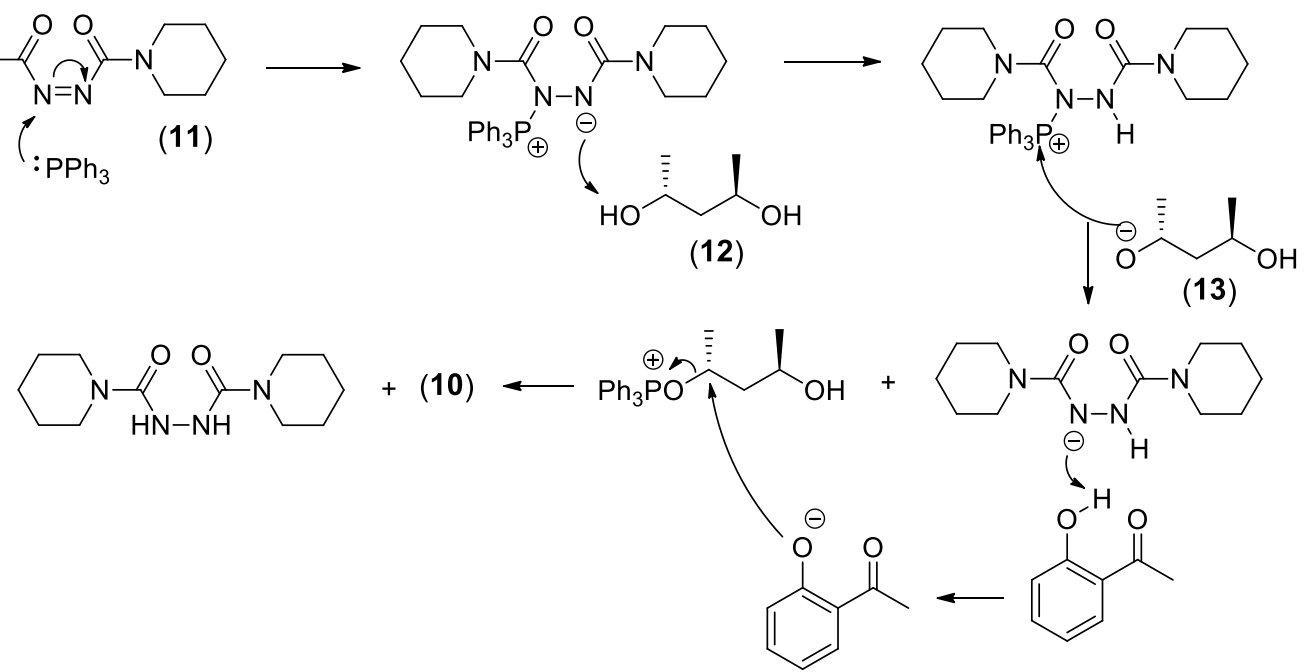

(14)

Figure 4 Mechanism of preparing (10) by using ADDP

\section{Modified Mitsunobu etherification reaction}

Due to unsuccessful $\mathrm{pH}$ relating approaches (reflux and/or a basic catalyse and stronger azo coupling use), steric influence of both substrate and diol is now turned to be considered. We then modified the Mitsunobu standard conditions by using sonication, a common method of doing reaction under sterically encumbered demanding substrates [14].

Submission (8), diol (12) and the Mitsunobu standard reagents into sonication conditions afforded the desired product moderately only in 10 minutes (Figure 5). 
<smiles>CC(=O)c1ccccc1O</smiles>

(8)<smiles>C[C@@H](O)C[C@@H](C)O</smiles><smiles>CC(=O)c1ccccc1O[C@@H](C)C[C@H](C)O</smiles>

$(10,64 \%)$

Figure 5 Synthesis of (10) through modified Mitsunobu etherification

Spectroscopy analysis of the product using 1H-NMR strongly confirmed the ether (10) structure with the appearance of enantiotopic AA'XX' system of $\mathrm{CH}_{2}$ under ddd splitting pattern (Figure 6). The chemical shift of these two enantiotopic proton is at 1.66 and $1.97 \mathrm{ppm}$.

\section{${ }^{1} \mathrm{H}-\mathrm{NMR}$}

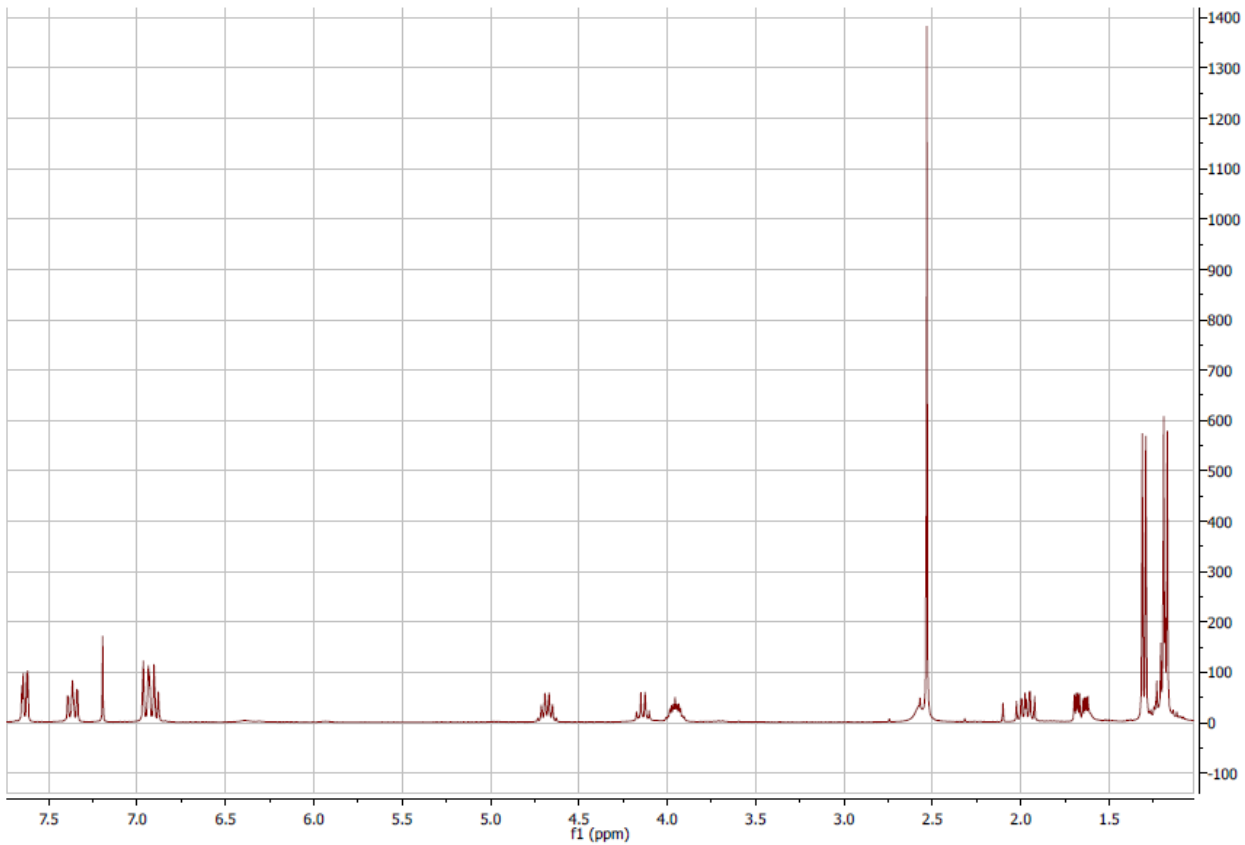

${ }^{13} \mathrm{C}-\mathrm{NMR}$

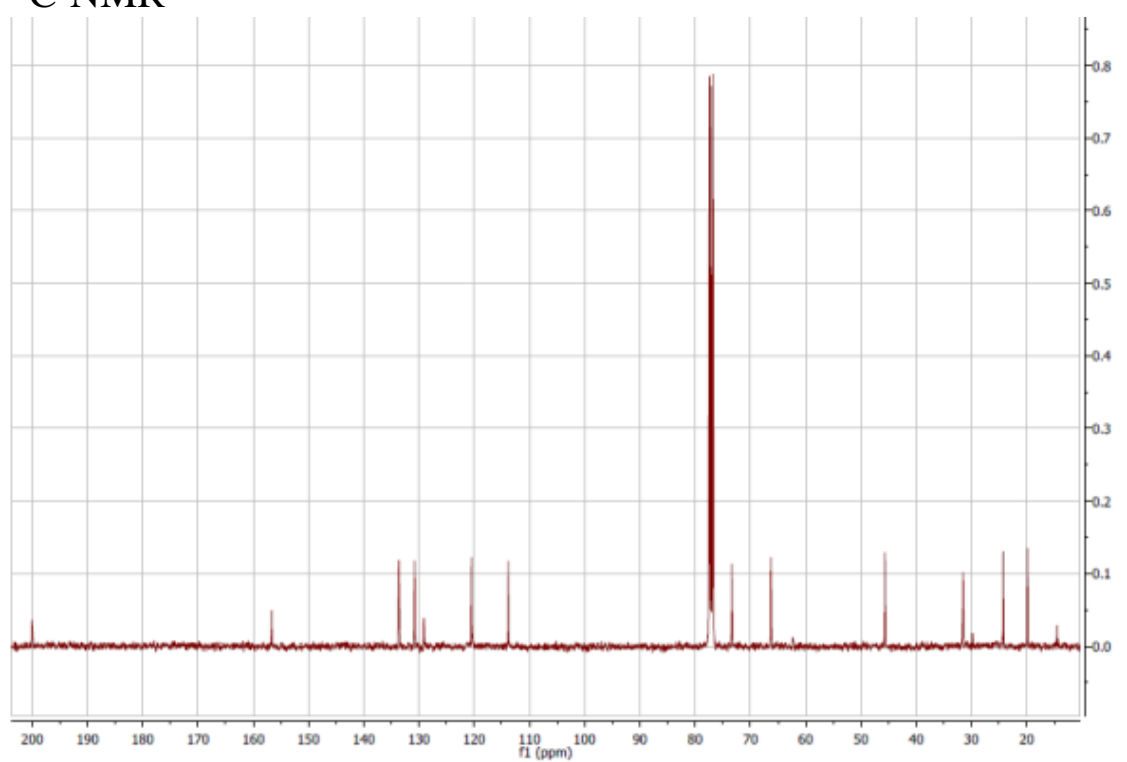

HRMS 


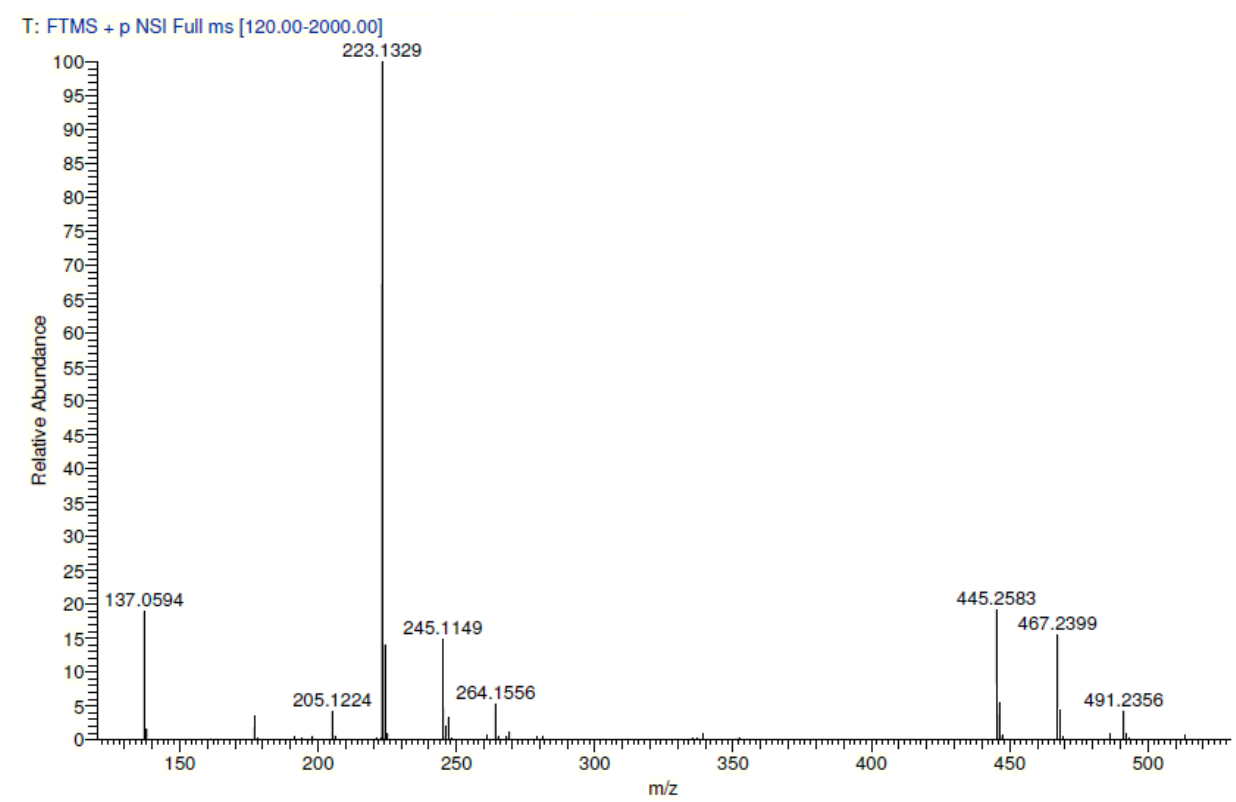

\section{FT-IR}

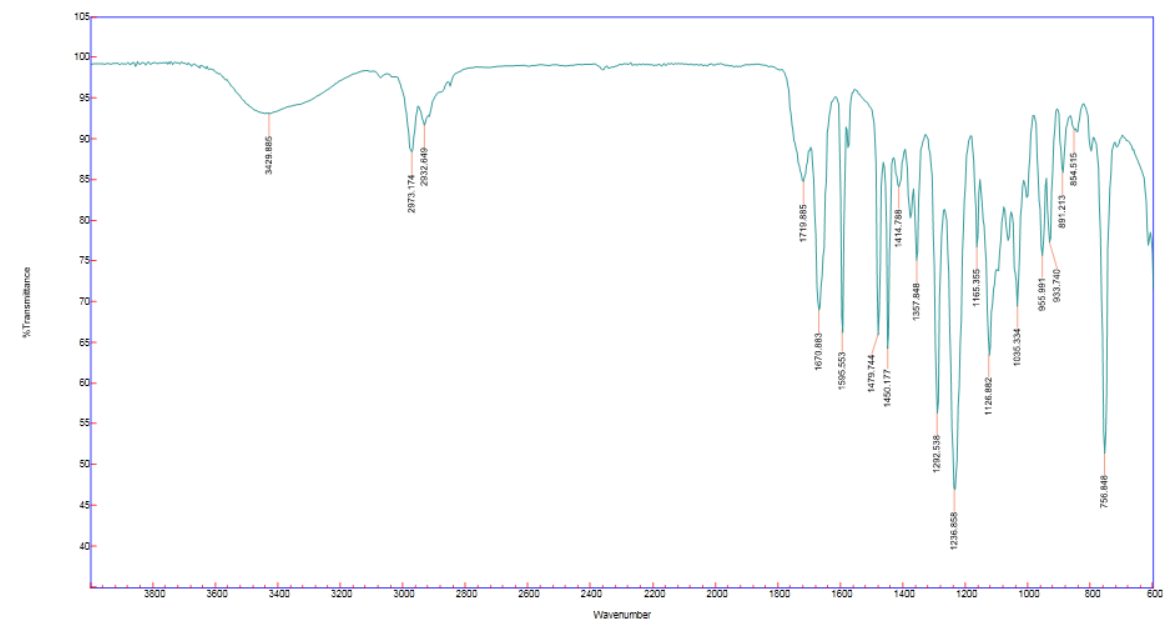

Figure 6 Spectroscopy data of (10)

A series of substituted aromatic ether was prepared under the modified Mitsunobu conditions following the success of preparing (10) (Table 3). According to Table 3, substituents (R) clearly showed substrate demanding electronic effects of the phenoxyketones undergoing Mitsunobu etherification reaction.<smiles>[R]c1ccc(C(C)=O)c(O)c1</smiles>

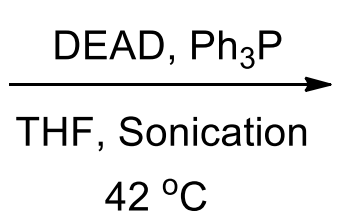<smiles>[R]c1ccc(C(C)=O)c(O[C@H](C)C[C@@H](C)O)c1</smiles> 
Table 3 Synthesis of substituted acetophenone ethers

\begin{tabular}{ccccc}
\hline Entry & $\mathrm{R}$ & $\begin{array}{c}\text { Time } \\
(\mathrm{min})^{*}\end{array}$ & Yield (\%) & Compound \\
\hline 1 & $4-\mathrm{OCH}_{3}$ & 25 & 17 & $(\mathbf{1 5})$ \\
2 & $5-\mathrm{NO}_{2}$ & 5 & 52 & $(\mathbf{1 6})$ \\
\hline
\end{tabular}

*optimisation time

Synthesis of benzophenone ethers

Engaging more in the steric and electronic effects of the Mitsunobu etherification of phenoxyketones, a more sterically hindered series, benzophenone and substituted benzophenones was selected to be examined. Due to Table 4, benzophenone and substituted benzophenones ether with (2R,4R)-pentanediol were successfully prepared under modified Mitsunobu conditions, varied from 6 to 27\%. Expectedly, this lower yield in comparison to that of the corresponding substituted 2-hydroxyacetophenone ((10), (15) and (16)) proved steric effect presence. Moreover, aromatic substituents clearly affirmed the electronic effect involvement.<smiles>O=C(c1ccccc1)c1ccc(P)cc1O</smiles>

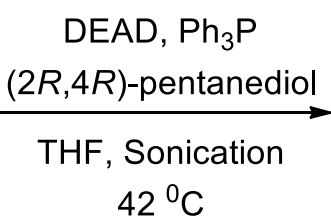<smiles>[R]c1ccc(C(=O)c2ccccc2)c(OC(C)CC(C)O)c1</smiles>

Table 4 Synthesis of benzophenone and substituted benzophenone ethers

\begin{tabular}{lllll}
\hline Entry & $\mathrm{R}$ & Time $(\mathrm{h})^{*}$ & Yield $(\%)$ & Compound \\
\hline 1 & $\mathrm{H}$ & 2 & 6 & $(\mathbf{1 7})$ \\
2 & $4-\mathrm{OMe}$ & 5 & 8 & $(\mathbf{1 8})$ \\
3 & $5-\mathrm{Cl}$ & 0.5 & 27 & $(\mathbf{1 9})$ \\
\hline
\end{tabular}

*optimisation time

\section{CONCLUSION}

Sterically hindered and intramolecular hydrogen bonding demanding substrates, 2-hydroxyacetophenones, benzophenone and substituted benzophenones were successfully etherified towards sonication assisted Mitsunobu reaction. The reaction was also controlled by steric hindrance, intramolecular hydrogen bonding and substrate electronic effects.

\section{ACKNOWLEDGEMENTS}

The authors thank The Directorate Research and Community Service Ministry of Research, Technology and Higher Education of The Republic of Indonesia for fundamental research grand (contract number 76/UN15.19.1/LT/2016).

\section{REFERENCES}

[1] R. Noyori, M. Ohta, Y. Hsiao, M. Kitamura, T. Ohta, and H. Takaya, "Asymmetric synthesis of isoquinoline alkaloids by homogeneous catalysis," J. Am. Chem. Soc., vol. 108, no. 22, pp. 7117-7119, Oct. 1986.

[2] K. Abdur-Rashid, M. Faatz, A. J. Lough, and R. H. Morris, "Catalytic Cycle for the Asymmetric Hydrogenation of Prochiral Ketones to Chiral Alcohols: Direct Hydride and Proton Transfer from Chiral Catalysts trans- 
$\mathrm{Ru}(\mathrm{H}) 2$ (diphosphine)(diamine) to Ketones and Direct Addition of Dihydrogen to the Resulting Hydridoami," $J$. Am. Chem. Soc., vol. 123, no. 30, pp. 7473-7474, Aug. 2001.

[3] R. Noyori, M. Yamakawa, and S. Hashiguchi, "Metal-Ligand Bifunctional Catalysis: A Nonclassical Mechanism for Asymmetric Hydrogen Transfer between Alcohols and Carbonyl Compounds," J. Org. Chem., vol. 66, no. 24, pp. 7931-7944, Nov. 2001.

[4] M. Smith, J. March, and J. March, March's advanced organic chemistry: reactions, mechanisms, and structure. New Jersey: Wiley, 2001.

[5] E. J. Corey and C. J. Helal, "Reduction of Carbonyl Compounds with Chiral Oxazaborolidine Catalysts: A New Paradigm for Enantioselective Catalysis and a Powerful New Synthetic Method," Angew. Chemie Int. Ed., vol. 37, no. 15, pp. 1986-2012, Aug. 1998.

[6] E. J. Corey and C. J. Helal, "Asymmetric Synthesis of (S)-Carbinoxamine. New Aspects of OxazaborolidineCatalyzed Enantioselective Carbony| Reduction," Tetrahedron Lett., vol. 37, no. 32, pp. 5675-5678, 1996.

[7] L. Kurti and B. Czako, Strategic Applications of Named Reactions in Organic Synthesis : Background and Detailed Mechanisms. London: Elsevier Science, 2005.

[8] A. Yamaguchi, S. Matsunaga, and M. Shibasaki, "Catalytic Asymmetric Synthesis of $\alpha$-Alkylidene- $\beta$-hydroxy Esters via Dynamic Kinetic Asymmetric Transformation Involving Ba-Catalyzed Direct Aldol Reaction,” J. Am. Chem. Soc., vol. 131, no. 31, pp. 10842-10843, Aug. 2009.

[9] T. Ooi, H. Otsuka, T. Miura, H. Ichikawa, and K. Maruoka, "Practical Oppenauer (OPP) Oxidation of Alcohols with a Modified Aluminum Catalyst," Org. Lett., vol. 4, no. 16, pp. 2669-2672, Aug. 2002.

[10] M. Fujita, Y. Takarada, T. Sugimura, and A. Tai, "Reliable chiral transfer through thermodynamic equilibrium of the intramolecular Meerwein-Ponndorf-Verley reduction and Oppenauer oxidation," Chem. Commun., vol. 0, no. 17 , pp. 1631-1632, Jan. 1997.

[11] H. Ç. Onar, B. Hasdemir, and A. Yusufo lu, "Asymmetric Meerwein-Ponndorf-Verley reduction of long chain keto alkanoic acid methyl esters," J. Serb. Chem. Soc, vol. 72, no. 5, pp. 421-427, 2007.

[12] P. S. Humphries, Q.-Q. T. Do, and D. M. Wilhite, "ADDP and PS-PPh3: an efficient Mitsunobu protocol for the preparation of pyridine ether PPAR agonists.," Beilstein J. Org. Chem., vol. 2, no. 2, p. 21, Oct. 2006.

[13] R. P. Patel and R. D. Patel, "Proton-ligand stability constants of some ortho-hydroxy phenones and their oximes," J. Inorg. Nucl. Chem., vol. 32, no. 8, pp. 2591-2600, Aug. 1970.

[14] S. D. Lepore and Y. He, "Use of Sonication for the Coupling of Sterically Hindered Substrates in the Phenolic Mitsunobu Reaction,” J. Org. Chem., vol. 68, no. 21, pp. 8261-8263, Oct. 2003. 